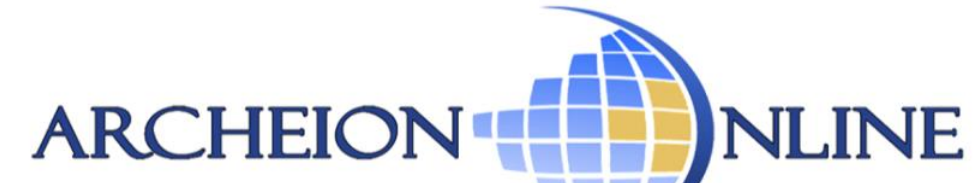 \\ ISSN 2318-6186
}

\section{OBJETOS DE CULTURA POPULAR: reflexões sobre a curadoria digital}

\author{
Ediane Toscano Galdino de Carvalho \\ Professora Departamento de Ciência da Informação/UFPB. Doutoranda no \\ PPGCI/UFPE. \\ E-mail: edianetgc@gmail.com \\ http://lattes.cnpq.br/8829826577169949
}

\section{Resumo}

Preservar objetos tridimensionais da cultura popular é preservar a memória social e a história de um povo que, mesmo marginalizado, é partícipe na construção da sociedade. A fim de facilitar e ampliar o acesso a esses objetos e às informações sobre os mesmos, diversas alternativas estão sendo construídas desde a fase de tratamento dos dados com a entrada de metadados, a digitalização, a visualização espacial em 3D, entre outras formas que possibilitam a eficiência e eficácia do acesso aos objetos. A migração dos dados para o ambiente digital ainda traz inquietações com relação às perdas de informações causadas por processos de digitalização, descrição e/ou preservação digital realizados de maneira adhoc. Neste cenário, o objetivo desse artigo é trazer reflexões acerca da curadoria digital de objetos tridimensionais da cultura popular, com foco na etapa de Descrição /Representação da informação desses objetos. Essa é uma pesquisa de cunho teórico e descritivo, buscando nas reflexões apontar caminhos para um entendimento sobre a curadoria e sua influência na preservação digital, no contexto do uso do ciclo de vida da curadoria digital do Digital Curation Centre (DCC), que abrange as etapas do ciclo de vida dos objetos e facilitam a adequação a cada instituição. As reflexões são abordadas sob a concepção do objeto musealizado, tendo na museologia caminhos possíveis para a descrição do referido tipo de objeto. A etapa de descrição para objetos de cultura popular deve ser bem planejada e os metadados bem definidos visando à recuperação com qualidade de imagens, sem perdas na integridade e abrangendo características que colaborem com o registro da originalidade e autenticidade do objeto e de sua contextualização histórica. Para tanto, são apresentadas recomendações no processo de descrição na curadoria digital.

Palavras-chave: Objetos de cultura popular. Curadoria digital. Descrição de objetos museais.

\section{INTRODUÇÃo}

O homem cada vez mais produz formas de compartilhamento de informações via internet a partir dos mais diversos tipos de registros, sejam eles manuais, impressos, analógicos, eletrônicos ou digitais.

Nesse processo de evolução, o objeto, visto como instrumento que assume ora a função de mediação, ora de protagonista na realização das mais diversas atividades sociais e culturais, estão interligados e são inerentes as ações humanas. 
As condições estabelecidas nesta relação homem e objeto conduziram a um novo tempo que para Miller (2013) permitiu que o homem melhorasse de vida, garantindo sua longevidade, desenvolvendo as relações de trabalho, as relações sociais, permitindo a criação de regras e normas que delimitam e dirigem a vida em sociedade. 0 autor enfatiza a necessidade da objetivação do que potencializa o ser humano enquanto pessoa criativa. Dá-se o nome a essa objetivação de mundo material que é criado e moldado a partir da natureza e das relações construídas socialmente desde a produção de objetos mais rudimentares até objetos tecnologicamente avançados.

Baudrillard (2002) afirma que os objetos (artesanais, utensílios, brinquedos, etc) têm uma singularidade em relação ao espaço que está constituído, são imbuídos de sentido e significado e, mesmo perdendo sua função original a partir das mais diversas circunstâncias durante a evolução da sociedade, ele nunca deixa de se transformar, adquirindo novas funções em outro ambiente e em outro tempo.

Uma das funções atribuídas aos objetos é a de preservação da memória, que para Rossi (2010, p. 23), esses objetos possibilitam lembrar o passado, as origens, e reconstituir a história a partir de uma necessidade do presente (ROSSI, 2010; MENEZES, 2007).

Assim, muitos desses objetos são negligenciados por fazerem parte de culturas que não são oficialmente reconhecidas dentro da estrutura histórica, social, cultural e política de uma sociedade. Eles são pouco ou quase nunca valorizados enquanto objetos relevantes para a construção histórica de um povo e por estarem inseridos em culturas menos favorecidas, são denominados de objetos de cultura popular.

Desse modo, se faz necessário que esses objetos que fazem parte da cultura popular não sejam esquecidos e que as futuras gerações conheçam a sua história e o contexto de sua criação e uso.

É pertinente manter a preservação desses objetos de cultura popular em sua forma física, como também migrá-los para plataformas digitais, por meio de digitalização, de forma a ampliar e facilitar o acesso aos mesmos e a informações sobre eles. Isso desencadeia preocupações em relação a falta de segurança, obsolescência e instabilidade do universo digital, que podem ocasionar perdas totais ou parciais desses objetos em formato digital, trazendo a necessidade de se pensar também na preservação 
inserida no contexto digital, de forma ampla, o que remete à curadoria digital. Esta é compreendida por Siebra et al. (2015) e Sayão e Sales (2012) como uma área que gerencia e preserva de forma abrangente o objeto digital, a partir de etapas que compõem ciclos de vida que iniciam com a criação ou digitalização do objeto e se repetem enquanto o objeto for de interesse de sua comunidade alvo.

No entanto, a fim de preservar o objeto de cultura popular no formato digital faz-se necessário reconhecer a complexidade do processo, pois entrelaça várias etapas como: planejamento, digitalização, organização e tratamento dos objetos, contextualização e descrição dos objetos, armazenamento, preservação, entre outras existentes no ciclo de vida dos objetos percebidos pela curadoria digital, tal como o ciclo do "Digital Curation Centre (DCC)" (ABBOTT, 2008).

Neste cenário, o objetivo desse artigo é trazer reflexões acerca da curadoria digital de objetos tridimensionais da cultura popular, com foco na etapa de representação da informação desses objetos. Focou-se nessa etapa por ela ser considerada uma das mais relevantes, visto que é a que colaborará tanto com a recuperação do objeto a posteriori, como com a compreensão do mesmo por parte da comunidade. As reflexões são abordadas sob a concepção de objetos musealizados, pois buscou-se na museologia caminhos possíveis para sua descrição desse tipo de objeto.

Esse artigo é de cunho teórico, com abordagem qualitativa e pretende contribuir, mesmo que de forma inicial, com a discussão sobre a curadoria de objetos tridimensionais da cultura popular, temática ainda pouco discutida na área de Ciência da Informação.

\section{UM OLHAR SOBRE OS OBJETOS TRIDIMENSIONAIS DA CULTURA POPULAR}

Será considerado o termo objeto para se referir a uma materialidade que têm forma tridimensional e assume a função informacional e de preservação da memória. A escolha do termo está baseada em Otlet (2018), quando considera objeto tudo que tenha caráter representativo a três dimensões e, eventualmente, em movimento. Mais especificamente, o foco do artigo está nos objetos tridimensionais da cultura popular, representados por: artesanatos decorativos em cerâmica, louças, ex-votos (objetos de 
promessas para santuários), brinquedos populares (em lata, reciclados e em madeira), lamparinas, candeeiros, máscaras de carnaval, tapeçaria, bordados, crochês, labirintos, bonecas de pano, bonecos de Cavalo Marinho, bonecos de Bau Bau, indumentárias de lapinhas, entre outros. Todos são objetos produzidos manualmente, a partir de uma necessidade advinda de usos do cotidiano. Observa-se que como expressões populares materializadas de várias formas, apresentam riqueza de detalhes e crenças e têm importância para a sociedade, não somente pelo registro da informação histórica, mas por serem um registro da memória social.

No entanto, por serem construídos em meio popular, são claramente subestimados em detrimento da construção de uma identidade, que não necessariamente é de origem da cultura oficial e acabam sendo relegados pela história ou têm destino ignorado. De fato, após a sua função utilitária, alguns desses objetos são esquecidos e/ou extraviados, alguns outros são expostos ou guardados nas próprias residências com função afetiva e outros tantos recolhidos e custodiados em unidades de informação, transformados em um contexto museal. Ainda que em melhor situação, a esses últimos, muitas vezes, não é dada a atenção merecida, sendo os objetos relegados a ambientes sem estrutura de organização, conservação e preservação.

Para compreender a marginalidade desse tipo de objeto, é necessário buscar o entendimento sobre o que é cultura e sua relação com o povo, mesmo sem o aprofundamento merecido da temática, visto não ser este, o foco do artigo.

Cultura é um termo impreciso, escorregadio, de difícil definição e que produz muitos equívocos e polêmicas (REALE, 1996; SANTOS, 1994, THOMPSOM, 1998; BURKE, 2010; WILLIAMS, 1992). A cultura pode ser vista enquanto processo produtivo, material e social (WILLIAMS, 1992), cultura material, cultura espiritual e cultura simbólica. Para Almeida Filho (2004, p. 5), "o trato dos fenômenos culturais não pode ser orientado por critérios de natureza universal. [...] cada sociedade possui uma fisionomia cultural própria".

Partindo da concepção de Laraia(2014), Edward Tylor cunhou a palavra culture advindo de um sentido etnográfico, onde o comportamento do homem é adquirido a partir de situações complexas cotidianas independente de transmissão genética e sim de 
um aprendizado, de uma endoculturaçãoำ 10 autor afirma que o conceito de cultura está em constante reconstrução, perpassando pelo determinismo biológico, determinismo geográfico, pela construção de comportamentos a partir do aprendizado e pelas considerações de uma cultura como sistema cognitivo, estruturais e simbólicos.

Para Burke (2010), a cultura tem limites indefinidos. No século XVIII o termo estava ligado a arte, a literatura e a música porém, ao longo do tempo, o termo tomou uma dimensão mais ampla e refere-se a "quase tudo que pode ser apreendido em uma dada sociedade, como comer, beber, andar, falar, silenciar [...] a história da cultura inclui agora a história das ações ou noções subjacentes a vida cotidiana". Esta é uma visão de uma sociedade que se modifica de acordo com cada época (BURKE, 2010, p. 25).

0 autor segue ainda na direção de que cultura é um "sistema de significados, atitudes e valores partilhados e as formas simbólicas (apresentações, objetos artesanais) em que eles são expressos ou encarnados" (BURKE, 2010, p. 24). Ou seja, leva em conta as construções cotidianas, a partir dos objetos materiais e apresentações como danças, músicas, entre outras. Entende a investigação da história a partir de aspectos sociais e culturais, levando em consideração os valores e os símbolos, em qualquer lugar que tenham sido construídos. Neste sentido admite que todos tem cultura.

Inserido neste contexto de construção cotidiana, Thompsom (1998) acredita que o costume é "sui generis" para os estudos sobre cultura, sejam costumes singulares ou plurais, dentro de um contexto total incluindo o simbólico, não deixando também de um olhar sobre as crenças. Para ele, o termo costume já foi empregado em tempos passados para demonstrar muito do que se considera atualmente sobre a palavra cultura (THOMPSOM, 1998). Os costumes podem ser uma ligação consensual ao que se tem sobre cultura, pois o modo de vida é determinante para delinear uma cultura.

Estudos a partir do século XVIII, marcado pelo reformismo iluminista, fazem uma diferenciação para a cultura no sentido de separação de que é oficialmente ligada a corte e de quem não é. Dessa forma, o termo cultura de elite foi estabelecido para a cultura transmitida formalmente em universidades e liceus da época, que eram frequentados apenas por uma parte da população, e cultura da não elite ou a cultura do

\footnotetext{
${ }^{1}$ Processo que se realiza a partir da educação, imitação, entre outras situações realizadas pelo homem.
} 
povo transmitida informalmente, voltada para uma cultura não oficial, formada por camponeses, artesãos, pastores e outros grupos sociais (BURKE, 2010). Também denominada de cultura subalterna por Gramsci (1979),

Considera-se então que a elite é atribuída ao povo nobre, culto, alfabetizado, dotado de poder religioso e econômico, entre os quais os costumes são tidos como refinados e modelados. Enquanto que a não elite é o povo anônimo, que não dispõe de poder econômico, e possuem costumes rudimentares, arcaicos, primitivos, cujas tradições são transmitidas oralmente, por não serem alfabetizados.

Dessa forma, os objetos também seguiam esta mesma direção, eram considerados de grande valor aqueles produzidos ou mesmo que não produzidos, mas utilizados pela nobreza, enquanto que os objetos produzidos e utilizados pelo povo que ficava a margem da nobreza não tinham valor histórico e cultural.

No entanto, os intelectuais, eruditos e membros da corte europeia do século XVIII descobrem no povo uma riqueza de seus usos, costumes e tradições como as manifestações das festas, contos, religião, música, entre outras, constituindo alvo de pesquisas e fazendo surgir um cenário histórico chamado de descoberta do povo, onde a preferência não estava mais nas ruínas antigas, mas nas maneiras e costumes advindos dos povos simples e incultos, que não faziam parte da corte. Faziam parte de um fenômeno exótico por suas características selvagens, naturais, livres das regras do classicismo e que apresentavam costumes mais simples. (BURQUE, 2010).

Burque (2010) chama a atenção para o fato de que o interesse pelo povo neste período teve como causa razões estéticas, intelectuais e políticas e que muitas pessoas que faziam parte da cultura da elite participavam de atividades do povo e, nesta perspectiva, a cultura do povo e a cultura de elite se misturavam, configurando uma situação heterogênea ${ }^{2}$. Ainda segundo Burke, Chartier também verifica esta assertiva quando enfatiza que objetos como ex-votos ou a literatura de cordel eram usados ou até “apropriados" tanto por nobres e clérigos, quanto por artesãos e camponeses. (BURKE, 2010, p.37).

\footnotetext{
${ }^{2}$ Ver multiculturalismo de Stuart Hall Hall, Stuart. Da diáspora: identidades e mediações culturais. Belo Horizonte: Universidade Federal de Minas Gerais, Brasília: UNESCO: UNESCO. 2003.
} 
Mas diante do que foi constituído socialmente parece não ter sido uma situação que tomou uma dimensão maior, pois os objetos e as apresentações do povo foram sendo suprimidas por outras construções sociais propagadas como universais. Mesmo com esta identificação de participação efetiva de vários grupos sociais em atividades do povo, autores como Williams (1992) e Thompson (1998; 2001), influenciados por Gramsci (1979), acreditavam na existência da hegemonia feita pelo poder (dominante) e também pelas produções culturais. Assim sendo, para aquele período, quem estivesse fora do grupo social dominante estava fadado ao não reconhecimento social.

Essa concepção é esclarecida quando, ao estudar a mudança de uma sociedade industrial manufatureira para uma sociedade artesanal na Grã Bretanha e na Índia durante o século XVIII, Thompson (2001, p. 230) afirma que ocorreu a transformação "de uma sociedade submetida a um acelerado ritmo de mudança para uma governada, numa extensão muito maior, pelo costume". Acredita ainda que é nos costumes que se revelam as principais respostas para as investigações sociais e culturais. Foi com este sentido de investigação dos costumes e ritos, por volta do século XVIII, que os folcloristas deram sua contribuição à preservação da memória de uma cultura que estava sendo esquecida.

Os folcloristas consideravam que as tradições populares podiam sobreviver ao passado. Para tanto classificaram os provérbios, as lendas, as estórias e os costumes populares, mas que, nem sempre, foram reveladas pelas pessoas que as produziram, ou seja, as coletas de dados eram realizadas sem uma metodologia estruturada e científica. Para eles, "fazer ciência significa classificar em gêneros e espécies a vida popular coletada" (ORTIZ, 1988, p.51).

Suas coletas se restringiam à descrição, não considerando os estudos a partir de uma totalidade do sistema social. Ainda assim, conseguiam trazer à tona as tradições que poderiam ser esquecidas. Corroborando com esta assertiva, Thompson (2001, p. 230) enfatiza que a não preocupação com a busca das narrativas ${ }^{3}$, criou um "abismo cultural e temporal", onde muitas vezes deslocaram "o contexto de uma cultura total" .

\footnotetext{
${ }^{3}$ Ver Valter Benjamim. A narrativa é uma forma de comunicação artesanal. 0 narrador recorre a experiências vividas por ele próprio ou relatadas por outras pessoas.
} 
No entanto, o autor não despreza a importância de suas coletas, visto que seus estudos foram base para relevantes investigações a respeito dos costumes e das tradições populares daquela época. Enfatiza que determinadas formas e rituais só podem ser compreendidos a partir de crenças e da "cultura consuetudinária" (THOMPSON, 2001, p. 241). Porém, Gramsci (1968) defende os estudos dos costumes a partir de uma concepção de mundo e da vida de forma crítica e consciente, observando além do que está no senso comum.

Na compreensão geral sobre cultura e povo, infere-se dizer que a cultura popular foi criada a partir de movimentos intelectuais de antropólogos, filósofos, folcloristas, sociólogos, etnólogos, que evocavam um sentimento de estudar inicialmente o exótico e as concepções de contradições sociais, preservando tradições de populações dispersas e propensas a serem esquecidas. Nesse sentido, parece ser pertinente atribuir aos estudiosos do século XVIII o fortalecimento da palavra cultura popular.

Dessa forma, é esclarecedor que existam objetos culturais que sejam vistos de forma diferente pela sociedade quando estes são protagonistas e ou mediadores em atividades relativas ao povo. Então esses objetos podem ser cunhados como objetos de cultura popular.

Para Marteleto (2007), os objetos podem ser considerados como "um artefato material e simbólico e que produz sentidos e fenômenos relacionados à cultura, gerando registro e memória, consequentemente precisam de organização, pedagogia e política".

Essa percepção indica uma perspectiva de objetos que estejam fora de seu ambiente original onde foi produzido e passou para um ambiente de preservação da memória com um potencial informacional geralmente inserido em museus ou colecionadores individuais.

BENJAMIN, Walter. 0 narrador. Considerações sobre a obra de Nikolai Leskov. In: Magia e técnica, arte e política. Ensaios sobre literatura e história da cultura. São Paulo: Brasiliense, 1985 (Obras escolhidas, v. 1), p. 197-221.

Archeion Online, João Pessoa, v.6, n.2, p.62-82, jan. / jun. 2019

http://periodicos.ufpb.br/ojs2/index.php/archeion. ISSN 2318-6186. Licença (cc) EY-NC-ND 


\section{DA MUSEALIZAÇÃo A CURADORIA DIGITAL: perspectivas na descrição de objetos de cultura popular}

Quando objetos de cultura popular são adquiridos por instituições museais a partir de compra, doação e coleta espontânea ou intencional passam pela fase de musealização que, segundo Menezes (1992, p.111), é o "processo de transformação do objeto em documento", ou seja, a transformação do objeto material em instrumento de testemunho da história, potencialmente informativo.

A partir daí, há a necessidade de realizar atividades técnicas e operacionais específicas que controlam e gerenciam as informações do acervo e sobre o acervo, permitindo a segurança e a preservação dos objetos no seu estado físico.

$\mathrm{Na}$ museologia essas atividades perpassam pela reunião de um "conjunto de informações sobre cada um dos seus itens e, por conseguinte, a representação destes por meio da palavra e da imagem (fotografia)" (FERREZ, 1994, p.65). Esse conjunto de informações é denominado de Documentação de Museus, onde estão os registros da criação, do histórico e da aquisição dos objetos pelo museu incluindo as normas, políticas e diretrizes do acervo e da instituição (MONTEIRO; LARA, 2013).

Esses registros possibilitam acesso às informações intrínsecas e extrínsecas dos objetos. Ferrez (1991) define informações intrínsecas como aquelas que são identificadas no próprio objeto em seu estado físico e dele descritas. Enquanto que para definir as extrínsecas, o autor toma o conceito emprestado de Peter Vam Menschi, para o qual informações extrínsecas são informações documentais e contextuais adquiridas de fontes externas ao próprio objeto, permitindo conhecimentos aprofundados e contextualizados dos documentos. Verifica-se então a importância desse último tipo de informação e surge a necessidade de planejar como ela será apreendida.

Atualmente, quando se fala em planejamento de uma instituição é indissociável considerar o uso das tecnologias de informação e comunicação nos processos técnicos, operacionais e administrativos, buscando maior eficiência e eficácia tanto para as pessoas que operam internamente a informação, quanto para os usuários que a buscam, mantendo a função social e cultural dessas instituições, tendo no objeto o meio de ligação entre o museu e o usuário.

Archeion Online, João Pessoa, v.6, n.2, p.62-82, jan. / jun. 2019

http://periodicos.ufpb.br/ojs2/index.php/archeion. ISSN 2318-6186. Licença (cc) EY-NC-ND 
As mudanças tecnológicas se ampliaram em várias frentes influenciando na comunicação, acesso, organização e tratamento técnico dos objetos, trazendo facilidades de cooperação de dados eletronicamente entre instituições e máquinas, além de novas preocupações relacionadas à preservação de objetos em meio digital.

A necessidade de preservação está vinculada a própria natureza do homem. Em ambiente físico os objetos enfrentam desgastes ou situações que incorrem na sua perda total ou parcial como incêndios, enchentes, desgastes, pragas, entre outros.

Dessa forma, a digitalização amplia as formas de preservação e acesso e cada vez mais produtos e serviços estão sendo inseridos em meio digital. Contudo, surgem as mesmas inquietações em relação à preservação tradicional, pois dependendo de como se preserva o objeto em meio digital, as ameaças podem surgir e ocasionar insegurança gerando inclusive perdas totais como alertado por Conway (2001, p.11) “A informação de forma digital - a evidência do mundo em que vivemos - é mais frágil que os fragmentos de papiros encontrados nas tumbas dos Faraós".

Esta declaração impõe certa preocupação em relação aos objetos de cultura popular inseridos em meio digital, pois, ao mesmo tempo em que há a possibilidade de reconstituição da memória, eles se tornam vulneráveis a perdas, logo, é necessário que sejam tomadas providências no tempo presente para assegurar a preservação da história do passado, visando à preservação e acesso no futuro.

Esta situação se faz relevante, pois Ferrez (1991, p.7) alerta que “A destruição das informações, sobretudo as de natureza extrínseca, quaisquer que sejam as causas, pode significar a perda definitiva e irreparável da história dos objetos”.

$\mathrm{Na}$ tentativa de preservar as informações em meio digital, a UNESCO publicou em 2003 um documento de autoria da Biblioteca Nacional da Austrália intitulado “Guidelines for the preservation of digital heritage", que são diretrizes, direcionadas a qualquer instituição, voltadas para a preservação do patrimônio digital ${ }^{4}$, o que expôs a necessidade de preservação digital.

Na última década vem sendo intensificado estudos sobre a preservação digital no contexto mais amplo que engloba a gestão ativa de objetos, antes e após a

\footnotetext{
${ }^{4}$ Disponível em: https://unesdoc.unesco.org/ark:/48223/pf0000130071
} 
preservação, sob a perspectiva da existência de um processo denominado de curadoria digital.

Defendendo a curadoria digital, Tibbo e Lee (2008) afirmam que curadoria é a gestão ativa da preservação de recursos digitais ao longo do seu ciclo de vida completo, visando o acesso, uso e reuso de objetos no tempo presente e futuro. Siebra, Borba e Miranda (2016, p. 23) afirmam que curadoria é uma "prática naturalmente interdisciplinar, combinando questões tecnológicas, comunicacionais, gerenciais, cognitivas, de geração de conhecimento e informacionais". A partir de então ratificam em suas conclusões o que defende a National Academy of Sciences, declarando que há a necessidade de "habilidades curatoriais" para lidar com o "gerenciamento, agregação de valor, armazenamento e preservação" e que é necessário o

desenvolvimento e difusão de normas e padrões que permitam o compartilhamento de informações digitais, a adoção de melhores práticas para melhorar e manter a qualidade da informação digital e o desenvolvimento de habilidades e técnicas de gestão, para proteger e preservar a informação digital (SIEBRA; BORBA; MIRANDA,2016, p.33).

Por isso, para a aplicação da curadoria digital foram desenvolvidos vários modelos para o ciclo de vida dos objetos digitais, como: Data Observation Network for Earth (DataONE) ${ }^{5}$, UK Data Archive ${ }^{6}$, Digital Curation Centre (DCC) ${ }^{7}$, entre outros. Cada modelo apresenta situações que inserem o contexto de curadoria, mas, diferenciam em relação ao envolvimento de aplicações sobre a preservação dos dados digitais. (SILVA; SIEBRA, 2017). Um dos métodos mais completos em termos de contemplar várias etapas que atende o processo curatorial é o Digital Curation Centre (DCC) ${ }^{8}$. (ABBOT, 2008).

Nesse sentido, para o presente artigo, o DCC será escolhido como modelo possível na realização de descrição dos dados de objetos de cultura popular.

Esse modelo possui diversas etapas visando garantir "que o objeto digital esteja acessível, desde o momento da sua criação, até a sua destinação final" ou guarda

\footnotetext{
${ }^{5}$ Ver: https://www.dataone.org/

${ }^{6}$ Ver: https://www.data-archive.ac.uk/

${ }^{7}$ Ver: http://www.dcc.ac.uk/resources/curation-lifecycle-model

${ }^{8}$ Conhecer a história do DCC em http://www.dcc.ac.uk/about-us/history-dcc/history-dcc
} 
permanente (SILVA; SIEBRA, 2017, p.5), define as responsabilidades de quem vai operar nas etapas, além de "construir uma estrutura de padrões e tecnologias para implementar" a curadoria. (DCC, 2019).

É apresentado em forma de gráfico, contendo as etapas consideradas na curadoria para uma eficiência na preservação dos dados. Segue abaixo o modelo.

Figura 1 - Modelo de Ciclo do DCC 9

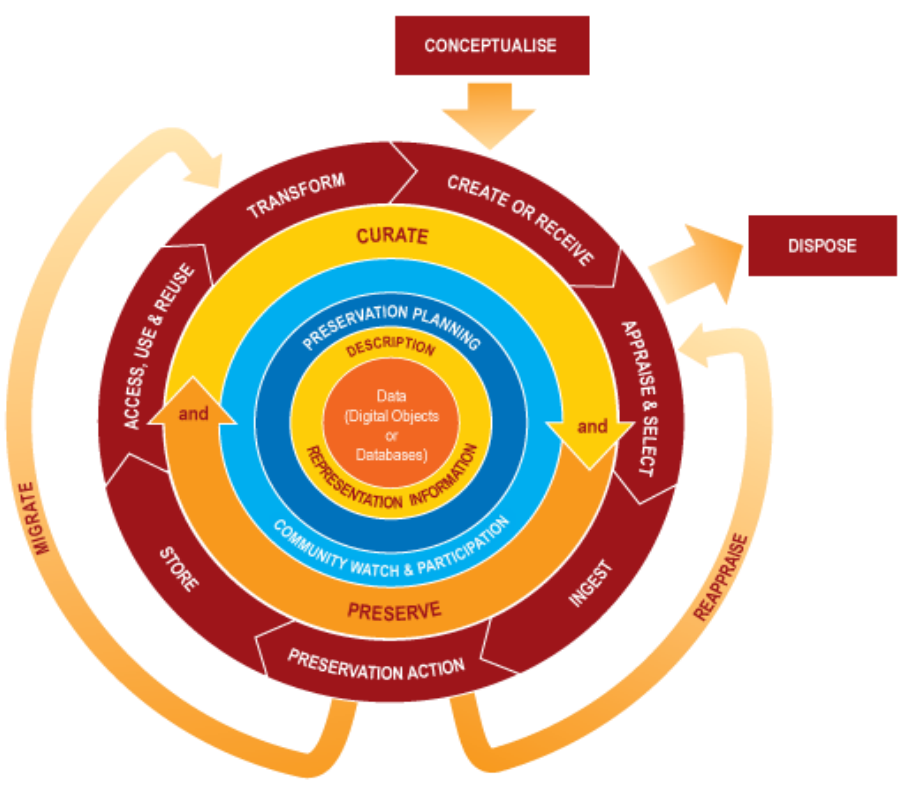

Fonte: DCC (2019)

O DCC é um modelo, que pode ser utilizado em diversos contextos. Por isso mesmo, é preciso que cada instituição ao realizar a curadoria adeque as etapas do modelo ao seu contexto podendo, dessa forma, suprimir etapas ou personalizar a execução das mesmas à sua realidade (infraestrutura, pessoal, recursos, etc.) e às características dos objetos a serem curados. Neste sentido, para a realização da curadoria digital em objetos de cultura popular deve-se levar em consideração situações a serem estabelecidas no projeto de planejamento que é a base estrutural da curadoria digital.

\footnotetext{
${ }^{9}$ Ver: http://www.dcc.ac.uk/digital-curation/digital-curation-faqs/dcc-curation-lifecycle-model
} 
Antes de estabelecer critérios de trabalho na curadoria digital sob o ponto de vista dos objetos de cultura popular a realização de um bom planejamento é fundamental, como em qualquer outro tipo de atividade gerencial. Para este caso especial, a infraestrutura é diferenciada, pois o processo depende de fatores como: o tamanho dos objetos, o local onde serão inseridos, as tecnologias de informação e comunicação utilizadas, em especial os scanners, as informações contextuais, além de outras características inerentes ao objeto e a preservação digital.

A partir das ações sequenciais do modelo do DCC $^{10}$ é importante observar as onze etapas do ciclo de vida da curadoria digital em relação aos objetos de cultura popular.

a) "Conceptualize" - nessa etapa deve-se formalizar documentos que definam políticas, requisitos legais e orientações para a criação do objeto digital, informando como os objetos serão manuseados, transportados (se for o caso), custodiados, selecionados quem tem direitos sobre os objetos, como serão realizadas (e se serão) as ações referentes à higienização/limpeza antes do processo de digitalização. Esta fase será base para todas as outras. Pode ainda definir a possibilidade de realizar a realidade aumentada para acessar os objetos e a utilização de web semântica.

b)“Create” - refere-se a criação dos objetos digitais. A pergunta como a digitalização ocorrerá? é fundamental nesta fase, tendo em vista os objetos terem dimensão tridimensional e não plana, requerendo a captação de vários ângulos espaciais entre outros fatores singulares ao tipo de objeto. Deve-se verificar a infraestrutura onde os objetos serão trabalhados, a organização, a preparação dos objetos e a definição dos parâmetros (tonalidade, resolução, descrição etc) para a digitalização.

c)“Access and use” é a fase de estruturação das ações que possibilitam a eficiência e eficácia no acesso a todos os objetos.

c)“Appraise \& Select” - nesta fase a seleção segue os critérios definidos previamente na primeira fase.

\footnotetext{
${ }^{10}$ Ver: http://www.dcc.ac.uk/digital-curation/what-digital-curation
} 
d) "Dispose" - é a fase onde os objetos que não estão selecionados para a curadoria de longo prazo podem ser eliminados, desde que estejam inseridos nos critérios definidos previamente na primeira fase.

e) "Ingest" - transferência dos objetos digitais para um ambiente confiável, também definido previamente na primeira fase.

f) "Preservation action" - nesta fase devem ser considerados diversos aspectos que garantam a longevidade da preservação como escolhas de repositórios confiáveis para backups, além de fiscalização nos riscos de perdas dos dados.

g) "Reappraise" - fase de reavaliação dos objetos que não estejam nos critérios definidos previamente.

h) "Store" - fase que leva em consideração a segurança de armazenamento dos dados digitalizados. Deve-se prever a expansão do armazenamento e das formas de backup, considerar a construção do espaço de armazenamento como o modelo do banco de dados. Considera-se ainda, questões relacionadas com a integridade, privacidade e a eficiência no armazenamento e na recuperação. Recomenda-se, portanto a construção de espaços para armazenar arquivos originais como forma de resguardar invasões de hackers ou perdas por outras situações e outros espaços para armazenar arquivos que estarão em uso do público.

i) "Access and Reuse" em relação a esta fase, faz necessário selecionar bem a ferramenta que vai ser utilizada para dar acesso aos dados armazenados, de forma que os metadados descritivos e as imagens estejam relacionados contribuindo para a representação do objeto. Além de selecionar ferramentas interoperáveis com interface amigável para o acesso eficaz e eficiente.

j) "Transform" - última fase considerada no ciclo da curadoria digital permite que novos objetos sejam criados a partir do original.

Estas fases da curadoria digital permitirão desenvolver ações de preservação, dependendo também de como a descrição será definida. 


\subsection{Recomendações iniciais para a descrição em ambiente digital de objetos da cultura popular a partir do modelo DCC}

Descrever os objetos em ambientes digitais envolve a adoção de padrões de metadados, como forma de especificar o que será registrado e onde será registrado.

No DCC a descrição é parte do processo de criação do objeto digital devendo ser planejada como atividade para todo o ciclo de vida, atribuindo "metadados administrativos, técnicos, estruturais, de representação, de acordo com os padrões apropriados", além de "assegurar a descrição adequada e o controle de longo prazo", assim como coletar e atribuir "informações de representação necessárias para o entendimento do dado e para a sua apresentação" (DCC, 2019, on-line. Tradução livre.).

Com relação à descrição de objetos tridimensionais de cultura popular ressaltase que muitos desses objetos não contemplam informações específicas importantes em sua identificação, como ano de produção e autoria, entre outras informações, demandando tempo e até investimentos para a realização de um levantamento das informações pertinentes para descrição e contextualização dos mesmos.

Por constituírem características de acervos museais, a descrição está direcionada para as normas estabelecidas nos museus não existindo uniformidade e cooperação entre essas instituições. Cada museu define sua forma individual de descrição, distinguindo das Bibliotecas que têm uniformização das normas internacionalmente. Para Marcondes (2013) essa não integração faz com que os museus não utilizem padrões estruturados de metadados, podendo ser um ponto de dificuldade para estabelecer processos de curadoria digital, tendo em vista que os padrões de metadados "formalizam a estrutura do elemento para garantir que os objetivos de uma comunidade de usuários possam ser cumpridos" (DCC, 2019, On-line, Tradução livre), além de colaborarem para interoperabilidade, compartilhamento, consistência e contextualização dos objetos, tendo como resultado uma recuperação eficaz, além de uma curadoria digital bem delineada.

Existem vários padrões de metadados que vem sendo utilizados para atender diversos tipos de materiais sejam bibliográficos, documentais ou objetos 
tridimensionais, sendo os mais utilizados em objetos de museus: o Dublin Core ${ }^{11}$, Canadian Heritage Information Network (CHIN) ${ }^{12}$, Art Museum Image Consortium (AMICO) ${ }^{13}$, The Visual Resources Association (VRA Core) ${ }^{14}$, Categories for the Description of Works of Art (CDWA)15, Europeana Data Model (EDM)16, Metadata Encoding and Transmission Standar (METS) ${ }^{17}$, entre outros.

Apesar da existência de vários padrões de metadados utilizados no contexto museal, não foi encontrada nas pesquisas bibliográficas a utilização de um modelo de curadoria digital em museus.

Assim sendo neste artigo é apresentado seis recomendações adaptadas das ações do ciclo de vida da curadoria digital para implementar padrões de metadados em objetos de cultura e possibilitar a descrição de objetos de cultura popular.

1) para definir as formas de descrição dos objetos é importante conhecer os padrões normativos de descrição de museus como a Standard Procedures for Collections Recording Used in Museums (SPECTRUM), e as Categorias de Informação do Comitê Internacional de Documentação do Conselho Internacional de Museus - (CIDOC/ICOM);

2) na digitalização de objetos culturais pode ser utilizada a estrutura das categorias principais do padrão The Visual Resources Association (VRA Core) para digitalização de imagens;

3) a descrição dos objetos deve considerar a criação de links entre os metadados e os recursos digitais descritos;

4) inserir no ambiente digital objetos em desuso e, muitas vezes, descontextualizados pode trazer dificuldade para descrição, pode-se fazer uso de recursos como pesquisas e entrevistas para enriquecer a descrição contextual dos objetos de cultura popular, visto que muitos deles são musealizados, mas não dispõem de informações suficientes para seu entendimento;

\footnotetext{
${ }^{11}$ Ver: http://dublincore.org/

${ }^{12}$ Ver: https://www.canada.ca/en/heritage-information-network.html

${ }^{13}$ Ver: http://www.amico.org/home.html

${ }^{14}$ Ver: http://core.vraweb.org/

${ }^{15}$ Ver: https://getty.edu/research/publications/electronic_publications/cdwa/definitions.pdf

${ }^{16}$ Ver: https://pro.europeana.eu/resources/standardization-tools/edm-documentation

${ }^{17}$ Ver: http://www.loc.gov/standards/mets/
} 
5) as ações de curadoria digital são pouco conhecidas no contexto museal, dessa forma é relevante definir o fluxo de trabalho, ou seja, a sequência lógica das atividades desenvolvidas para a qualidade do produto final;

6) qualificar e especializar os recursos humanos na área de objetos de cultura popular na perspectiva de garantir a eficiência e a eficácia na qualidade da descrição.

Para a utilização de um padrão específico de descrição de objetos tridimensionais de cultura popular a recomendação é escolher o que seja eficiente na interoperabilidade e apresente condições de implantação de arquivos que contemplem imagem em 3D, áudio e vídeo, além de descrição de conteúdo e a aplicação de web semântica, permitindo a amplitude na área descritiva, tendo em vista que cada objeto tem características diferentes para diversas localidades. E, quanto mais dados relevantes, mais enriquece a recuperação e a construção da memória sobre o objeto e o seu contexto social e cultural.

\section{CONSIDERAÇÕES FINAIS}

É pertinente considerar que os desafios a serem enfrentados para implementação das práticas de curadoria e de preservação em meio digital são inúmeros, porém devem ser enfrentados pelas instituições que disponibilizem seus dados e objetos em ambientes digitais.

A curadoria digital provoca questionamentos e gera insegurança nos profissionais que atuam com a preservação de objetos museais, pois trazem novas perspectivas e requerem o repensar das formas de trabalho. Porém, já existem algumas iniciativas internacionais no sentido de aprofundar essa temática em museus, como é o caso do Programa de Estudos de Museus da Universidade Johns Hopkins (JHU) que em 2015 promoveu um encontro com profissionais de bibliotecas arquivos e museus, no sentido de discutir a curadoria digital no contexto de museus de arte, aumentando a sensibilização sobre os cuidados e preservação da crescente demanda de materiais digitais nesses museus (ZORICH, 2015). 
Durante o ciclo de vida dos objetos digitais, no processo de implantação da curadoria, o modelo DCC pode ser aplicado para qualquer objeto tridimensional, incluindo os objetos de cultura popular.

O DCC permite ainda que a curadoria digital e a preservação sejam realizadas de forma cuidadosa no sentido de conhecer plenamente as ações para não perder o tempo e não dispender recursos.

A fase de descrição é realizada para todo o ciclo de vida do objeto, devido ao seu valor histórico, social, cultural e afetivo, visto que não existe a previsão de um descarte como ocorre nos documentos arquivísticos que leva em consideração a tabela de temporalidade e a previsibilidade de descartar o documento digitalizado.

Para a fase de criação do objeto digital, os metadados devem ser expandidos observando o contexto histórico, social e cultural do objeto, definindo-o no espaço e no tempo, podendo descrever sua região, o seu período de criação e outras informações contextuais, consistindo em informações extrínsecas, obtidas a partir de pesquisas documentais ou por meio da oralidade com especialistas ou conhecedores do objeto, no sentido de constituir uma narrativa histórica desses objetos.

Vale salientar que as recomendações apresentadas neste artigo, representam o início de novas pesquisas sobre a temática, sabendo que os desafios na descrição de dados independente do tipo de documento sempre foi motivo de estudos e que certamente a descrição envolvendo a curadoria digital ainda tem muito a evoluir.

\section{OBJECTS OF POPULAR CULTURE: reflections on digital curatorship}

\section{Abstract}

To preserve three-dimensional objects of popular culture is to preserve the social memory and history of a people who, even if marginalized, are participants in the construction of society. In order to facilitate and expand access to these objects and information about them, several alternatives are being built from the stage of data treatment with the input of metadata, digitalization, 3D spatial visualization, among other ways that enable the efficiency and effectiveness of access to objects. The migration of data to the digital environment still brings concerns regarding the loss of information caused by processes of digitalization, description and/or digital preservation performed in an adhoc manner. In this scenario, the objective of this article is to bring reflections about the digital curation of three-dimensional objects of popular culture, focusing on the stage of Description / Representation of information of these objects. This is a theoretical and descriptive research, seeking in the reflections to point out ways to an 
understanding about the curation and its influence on digital preservation, in the context of the use of the life cycle of digital curatorship of the Digital Curation Centre (DCC), which covers the stages of the life cycle of objects and facilitate the adaptation to each institution. The reflections are addressed under the conception of the musealized object, having in museology possible paths for the description of that type of object. The description step for objects of popular culture should be well planned and the metadata well defined aiming at the recovery with quality of images, without loss in integrity and covering characteristics that collaborate with the registration of the originality and authenticity of the object and its historical contextualization. To this end, recommendations are presented in the process of description in the digital curation.

Keywords: Objects of popular culture. Digital curation. Description of museum objects.

\section{REFERÊNCIAS}

ABBOT, Dayse. What is digital curation? DCC Briefing Papers: Introduction to Curation. Edinburgh: Digital Curation Centre. 2008. Disponível em:

<http://www.dcc.ac.uk/resources/briefing-papers/introduction-curation/what-digitalcuration>. Acesso em: 02 abr. 2019

ALMEIDA FILHO, A. Sociedade e cultura em evolução. Campinas, SP: Edicamp, 2004.

BAUDRILLARD, J. 0 sistema dos objetos. São Paulo: Perspectiva, 1973.

BURKE, P. Cultura popular na idade moderna: Europa, 1500-1800. Trad. Denise Bottman. São Paulo: Companhia das Letras, 2010. Disponível em: $<$ http://www.portalconservador.com/livros/Peter-Burke-Cultura-Popular-na-IdadeModerna.pdf>. Acesso em: 14 de mar. de 2019.

CONWAY, P. Preservação no universo digital. 2. ed. Rio de Janeiro: Projeto Conservação Preventiva em Bibliotecas e Arquivos, 2001. Versão digitalizada.

DCC. DIGITAL CURATION CENTRE. Disponível em: <http://www.dcc.ac.uk/digitalcuration>. Acesso em: 20 fev. 2019.

The DCC Curation Lifecycle Model. Disponível em:

<http://www.dcc.ac.uk/sites/default/files/documents/publications/DCCLifecycle.pdf>. Acesso em: 20 fev. 2019.

FERREZ, H. D. Documentação Museológica: teoria para uma Boa Prática. In: FÓRUM DE MUSEUS DO NORDESTE, 4. Anais... Recife, 1991. Disponível em: $<$ https://docgo.net/viewdoc.html?utm_source=documentacao-museologica-helenadodd-ferrez> Acesso em: 05 jan. 2019.

GRAMSCI, A. A formação dos intelectuais. In: Os intelectuais e a organização da cultura. 3. ed. Rio de Janeiro: Civilização Brasileira, 1979, p. 03-23. 
LARAIA, Roque de Barros. Cultura: um conceito antropológico. 26 reimp. Rio de Jan., Zahar, 2014.

MARCONDES, C. H. Interligando acervos digitais na Web em arquivos, bibliotecas e museus. In: SEMINÁRIO INTERNACIONAL ARQUIVOS DE MUSEUS E PESQUISA: humanidades e interfaces digitais, 3., 2013, São Paulo. Anais... São Paulo: Grupo de Trabalho Arquivo de Museus e Pesquisas, 2013. p. 9-30.

MARTELETO, R. M. Lugar da cultura no campo de estudos da informação: cenários prospectivos. In: LARA, M. L. G.; FUJINO, A.; NORONHA, D. P. (Org.) Informação e contemporaneidade: perspectivas. São Paulo: Néctar; ECA/USP, 2007, p. 13-26.

MENEZES, Ulpinano T. Bezerra de. A história, cativa da memória? Par um mapeamento da memória no campo das Ciências Sociais. Rev. Inst. Est. Bras. São Paulo, v. 34, p. 9-24, 1992.

. Os paradoxos da Memória In: MIRANDA, Danilo Santos de. Memória e Cultura: a importância na formação cultural humana. São Paulo: SESC, SP, 2007. p. 13-33.

MILLER, Daniel. Trecos, troços e coisas: estudos antropológicos sobre a cultura material. Rio de Janeiro: Zahar, 2013.

MONTEIRO, J.; LARA, M. G. L. de. A noção de documentação em museus nas normas SPECTRUM e CIDOC/ICOM. In: ENCONTRO NACIONAL DE PESQUISA EM CIÊNCIA DA INFORMAÇÃO, 15, 2013, Belo Horizonte. Anais... Belo Horizonte: UFMG, 2014.

ORTIZ, Renato. Notas históricas sobre o conceito de cultura popular. 1988.

OTLET, P. Tratado de documentação: o livro sobre o livro. Teoria e prática. Brasília: Briquet de Lemos, 2018. E-book.

REALE, M. Paradigmas da cultura contemporânea. São Paulo: Saraiva, 1996.

ROSSI, Paolo. 0 passado, a memória o esquecimento: seis ensaios da história das ideias. Trad. Nilcom Moulim. São Paulo: Editora UNESP, 2010.

SANTOS, J. L. dos. 0 que é cultura. 14. ed. São Paulo: Brasiliense, 1994. (Coleção Primeiros Passos, 110).

SAYÃO, L. F.; SALES, L. F. Patamar para preservação de dados digitais de pesquisa. Inf. \& Soc.:Est., João Pessoa, v.22, n.3, p. 179-191, set./dez. 2012.

SIEBRA, S.de A et al. Curadoria digital: além da questão da preservação digital. In: ENCONTRO NACIONAL DE PESQUISA EM CIÊNCIA DA INFORMAÇÃO, 14. 2013. Anais... Disponível em: 
<http://enancib.sites.ufsc.br/index.php/enancib2013/XIVenancib/paper/viewFile/317 /320>. Acesso em: 20 abr. 2019.

SIEBRA, S. de A. ; BORBA, V. da R.; MIRANDA, M. K. F. de Oliveira. Curadoria Digital: um termo interdisciplinar. Informação \& Tecnologia (ITEC), Marília/João Pessoa, v.3, n.2, p.21-38, jul./dez. 2016. Disponível em:

<http://www.periodicos.ufpb.br/index.php/itec/article/view/38408>. Acesso em: 03 jan. 2019.

SILVA, F. M. de O.; SIEBRA, S. de A. Análise de modelos de ciclos de vida para curadoria de objetos digitais. In: ENCONTRO NACIONAL DE PESQUISA EM CIÊNCIA DA INFORMAÇÃO(ENANCIB), 28. Marília, 2017.

THOMPSON, E. P. Folclore, antropologia e história social. Trad. Antonio Luigi Negro. In: .As peculiaridades dos ingleses e outros artigos. Org. Antonio Luigi Negro e Sergio Silva. Campinas: Ed. da UNICAMP, 2001, p. 227-267.

THOMPSON, E. P. Introdução: costume e cultura; Patrícios e plebeus; Tempo, disciplina de trabalho e capitalismo industrial In: - Costumes em comum. São Paulo: Companhia das Letras, 1998. p. 13-24.

TIBBO, H. R.; HANK, C.; LEE, C. A. Challenges, curricula, and competencies: researcher and practitioner perspectives for informing the development of a digital curation curriculum. In: ARCHIVING 2008, Bern, 2008. Final Program and Proceedings. Springfield: Society for Imaging Science and Technology, 2008.

WILLIAMS, R. Cultura. Rio de Janeiro: Paz e Terra, 1992. 239 p.

ZORICH, D. Report of the summit on digital curation in art museums. 2015.

Washington, DC: Universidade Johns Hopkins (JHU) . https://advanced.jhu.edu/wpcontent/uploads/2016/04/digitalCuration_summitReport10_2015.pdf 